\title{
Effect of diets containing a purified soybean trypsin inhibitor on growth performance, digestive proteases and intestinal histology in juvenile sea bream
} (Sparus aurata L.)

\author{
Ester Santigosa ${ }^{1 *}$, Miguel Ángel Sáenz de Rodrigáñez ${ }^{2}$, Ana Rodiles $^{3}$, Fernando García Barroso², \\ Francisco Javier Alarcón ${ }^{2}$ \\ ${ }^{1}$ Department of Physiology, Faculty of Biology, University of Barcelona, Barcelona, Spain \\ ${ }^{2}$ Department of Applied Biology, University of Almería, Almería, Spain \\ ${ }^{3}$ IFAPA Aguas del Pino, Cartaya-Punta Umbría, Huelva, Spain
}

Correspondence: F J Alarcón, Department of Applied Biology, University of Almería, 04120 Almería, Spain. E-mail: falarcon@ual.es *Present address: E Santigosa, Ifremer, UMR 1067 Fish Nutrition Unit, BP 70, 29280 Plouzane, France.

\begin{abstract}
Juvenile sea bream were fed on diets containing $0.0,2.0$ or $4.0 \mathrm{~g} \mathrm{~kg}^{-1}$ of a soybean trypsin inhibitor (SBTI) for 30 days. The growth performance, total protease activity and intestinal histology were studied after 0, 15 and 30 days of dietary treatment. No significant differences were found in the weight gain, specific growth rate (SGR) and feed conversion rate in fish fed on inhibitor-supplemented diets when compared with those fed on an inhibitor-free diet. Only the SGR at day 15 decreased significantly with protease inhibitor inclusion, although this effect was not observed at day 30. In relation to proteolytic activity at day 15 , the total protease activity in the distal intestine decreased in fish fed on inhibitor-supplemented diets. Zymograms of these extracts showed that the SBTI reduced the intensity of some proteolytic fractions in the distal intestine. A noticeable reduction in the protease activity of the intestinal content in fish fed on the highest level of soybean inhibitor $\left(4.0 \mathrm{~g} \mathrm{~kg}^{-1}\right)$ was also observed. However, at day 30, the inhibition effect on these active bands was not detected, and the total protease activity was similar to that in fish fed on an inhibitor-free diet. Histological examination revealed no perceptible differences in the intestinal structure between any of the diet groups. In addition, all fish were maintained under experimentation for 10 more days and fed on an inhibitor-free diet to determine whether the possible effects caused by the protease inhibitor could be reverted. The administration of SBTI-supplemented diets did not
\end{abstract}

affect sea bream growth performance or intestine histology after 30 days, and only a decrease in the total alkaline protease activity was found at day 15 .

Keywords: digestive proteases, gilthead sea bream, growth, intestine histology, SDS-PAGE, trypsin inhibitor

\section{Introduction}

A growing limitation of fish meal supplies is leading to the search for alternative protein sources for aquafeeds. Plant protein ingredients are reasonably priced, and have been widely studied due to their current worldwide distribution and steady supply. Soybean meal is the most commonly used plant protein in aquafeeds because its amino acid composition meets fish amino acid requirements (Lim \& Akiyama 1992). However, fish meal replacement by soybean meal presents certain challenges, such as the reduction in some effects caused by antinutritional factors present in this plant protein source (Francis, Makkar \& Becker 2001), which may limit its use in diets for carnivorous fish species (Makkar 1993).

Soybean meal antinutritional factors can impair digestion processes (Kissil, Lupatsch, Higgs \& Hardy 2000) by binding protease inhibitors to digestive enzymes (Moyano, Martínez, Díaz \& Alarcón 1999) or by the formation of phytic acid-protein complexes (Richardson, Higgs, Beames \& McBride 1985). The use 
of soybean has also been related to hypocholesterolaemia (Kaushik, Cravedi, Lalles, Sumpter, Fauconneau \& Laroche 1995), hepatic hypertrophy and induced vitellogenesis (Pelissero, Bennetau, Babin, Lemenn \& Dunogues 1991) or intestinal lesions (Refstie, Korson, Storebakken, Baeverfjord, Lein \& Roem 2000). Furthermore, these effects may lead to reduced growth performance ratios, as described for sea bream (Kissil et al. 2000), rainbow trout (Ostaszewska, Dabrowski, Palacios, Olejniczak \& Wieczorek 2005) or tilapia (El-Sayed, Martínez \& Moyano 2000).

In any event, studies related to soybean inclusion effects on fish metabolism and growth performance are controversial, because the inclusion of soybean meal in fish diets reduced growth performance in some trials (Dabrowski, Poczyczynski, Kock \& Berger 1989; Gallagher 1994; Gomes, Rema \& Kaushik 1995; El-Sayed et al. 2000), while in others, the specific growth rate (SGR) was maintained (Sanz, Morales, de la Higuera \& Cardenete 1994; Kaushik et al. 1995; Bonaldo, Roem, Fagioli, Pecchini, Cipollini \& Gatta 2008) or even improved (Oliva-Teles, Gouveia, Gomes \& Rema 1994). This variation in the results can be explained by differences in the size of the animals (Choi, Wang, Park, Lim, Kim, Bai \& Shin 2004; Venou, Alexis, Fountoulaki \& Haralabous 2006), plant protein inclusion levels (Krogdahl, Lea \& Olli 1994; Robaina, Izquierdo, Moyano, Socorro, Vergara, Montero \& Fernández-Palacios 1995; Olsen, Hansen, Roselund, Hemre, Mayhew, Knudsen, Eroldogan, Myklebust \& Karlsen 2007) and species-specific sensitivity to alternative raw sources (Krogdahl \& Holm 1983; Moyano et al. 1999; Alarcón, García-Carreño \& Navarrete del Toro 2001). It may also depend on the origin and treatment of the soybean meal source used in each case (Refstie, Storebakken \& Roem 1998; Francis et al. 2001).

Biochemical and histological alterations described in fish meal replacement trials are attributed to residual antinutritional factors present in soybean meal or soybean derivates used in experimental diets. However, there is scarce information about the role of specific soybean meal antinutritional factors involved in each specific alteration (Krogdahl et al. 1994; Olli, Hjelmeland \& Krogdal 1994; Refstie et al. 2000). It should be remembered that most antinutritional factors described can be eliminated from raw materials by using different technological processes (Francis et al. 2001). Nevertheless, some of them are heat-stable, and may affect digestion processes when only conventional treatments are undertaken, such as the Bowman-Birk protease inhibitor (Alarcón, Moyano \& Díaz 1999), soya saponins (Knudsen, Ron,
Baardsen, Smedsyaard, Koppe \& Frokiaer 2006) or phytic acid (Anderson \& Wolf 1995). Moreover, synergism has been described between lectins, commonly present in legume seeds, and other antinutritional factors (Grant 1991).

As only a few studies have analysed the specific effects of each antinutritional factor in detail (Krogdahl et al. 1994; Olli et al. 1994; Sveier, Kuamme \& Raae 2001), the study of effects related to individual antinutritive compounds on fish physiological processes is of interest. Such studies are needed in order to elucidate their consequences, and to collect the necessary information to minimize their effects when fish are fed on diets containing plant protein ingredients.

Differences in the results from previous studies involving diets containing soybean meal, together with in vitro studies proving inhibition of digestive proteases by soybean meal extracts (Alarcón et al. 1999), make it necessary to study the in vivo consequences when juvenile sea bream are fed on diets containing soybean-purified antinutritional factors.

The present study was developed to evaluate the effects on growth performance, digestive protease activity and intestine morphology of gilthead sea bream fed on purified soybean trypsin inhibitor (SBTI)-supplemented diets during a mid-term trial.

\section{Materials and methods}

\section{Animals}

One hundred and eighty-nine living sea bream (Sparus aurata) fingerlings obtained from a commercial farm (Predomar S.L., Almería, Spain) were acclimatized in an indoor marine water system. Fish were fed on a commercial diet (Skretting $2 \mathrm{~mm}, 45 \%$ protein, $12 \%$ lipid) before the onset of the experiment. After 15 days, the fish $(13.5 \pm 0.14 \mathrm{~g})$ were randomly distributed into nine experimental tanks $(50 \mathrm{~L}$; 21 fish per tank) connected to a closed recirculating system consisting of a mechanical sand filter, ultraviolet lights and a biofilter. The system was maintained at a constant temperature $\left(21 \pm 1^{\circ} \mathrm{C}\right)$, a constant salinity ( $30 \pm 2$ ppm) and a $12 \mathrm{~h}: 12 \mathrm{~h}$ light:dark photoperiod. Water quality was maintained by physical filters and UV radiation. The total ammonia concentration was measured daily and did not exceed $0.2-0.3 \mathrm{mg} \mathrm{L}^{-1}$.

\section{Diets}

A commercial aquafeed (Table 1) was ground, and after adding 0.0, 2.0 or $4.0 \mathrm{~g} \mathrm{~kg}^{-1}$ of purified soybean 
Aquaculture Research, 2010, 41, e187-e198 Effect of SBTI on growth and digestive proteases of sea bream E Santigosa et al.

Table 1 Chemical composition of the experimental diets

\begin{tabular}{lccc}
\hline & Control & SBTI-1 & SBTI-2 \\
\hline Protein (\%)* & & 45.0 & \\
Lipid (\%) $\dagger$ & & 18.0 & \\
Cellulose (\%) & & 1.7 & \\
Ash (\%) & & 8.0 & \\
Estimated TIA (mg g feed & -1 \\
\end{tabular}

*Based on fish meal LT-94 $(65 \% \mathrm{w} / \mathrm{w})$.

$\dashv$ From fish oil.

Diets were supplemented with minerals and vitamins according to NRC recommendations (1993).

TIA, trypsin inhibitor activity.

trypsin inhibitor (SBTI-93620, $10000 \mathrm{Umg}^{-1}$; Sigma-Aldrich, Madrid, Spain), was repelleted $(2 \mathrm{~mm})$ to obtain diet control, SBTI-1 and SBTI-2 respectively. Diet samples were collected to measure protease inhibitor activity and stored at $-20^{\circ} \mathrm{C}$.

During the feeding trial, three triplicate groups of fish were fed $4 \%$ of tank biomass of the corresponding experimental diet twice a day (09:00 and 16:00 hours) for 30 days. After this period, the remaining fish in the three treatments were fed on the control diet for an additional period of 10 days, to determine whether any possible effects of SBTI on the growth rates or intestinal histology could be reversed by the administration of an inhibitor-free diet.

\section{Protease inhibitor activity in diets}

The inhibitory effect of experimental feeds (control, SBTI-1 and SBTI-2) on digestive sea bream acid and alkaline proteases of the initial samples (SO) was evaluated according to Alarcón et al. (2001). Twenty microlitres of a dilution series of feed extracts (providing amounts of experimental diet that ranged from 0 to $20 \mu \mathrm{g}$ ) were incubated with $20 \mu \mathrm{L}$ of enzymatic extracts providing a fixed amount of activity (digestive extracts had been adjusted previously to provide a 0.5 increase of absorbance at $280 \mathrm{~nm}$ in $30 \mathrm{~min}$ at $25^{\circ} \mathrm{C}$ ) in $0.5 \mathrm{~mL}$ of $0.1 \mathrm{M}$ glycine- $\mathrm{HCl} \mathrm{pH}$ 2.0 (for acid proteases) or $50 \mathrm{mM}$ Tris-HCl pH 9.0 (for alkaline proteases) for $1 \mathrm{~h}$ at $25^{\circ} \mathrm{C}$. After that, the residual protease activity was evaluated by adding $0.5 \mathrm{~mL}$ of substrate (haemoglobin or casein for acid and alkaline proteases respectively). Controls were prepared by adding the equivalent amount of distilled water instead of aqueous feed extracts. Enzyme inhibition was assessed as the percentage of residual activity by comparing it with the control assay. Porcine trypsin (Sigma-Aldrich T-0303;
13000-20000 $\mathrm{Umg}^{-1}$ protein) was included as an internal control in the inhibition assay.

\section{Sampling}

During the growth trial, four samplings were carried out at days $0,15,30$ and 40 (SO, S15, S30 and S40 respectively) and individual fish weight was recorded in 12-h starved fish. The next day, after S0, S15 and S30 fish weight determination, additional samplings were performed $3 \mathrm{~h}$ after manual feeding to obtain fish digestive tissues. Four animals per tank were randomly selected and sacrificed according to the requirements in Council Directive 86/609/EEC after isoeugenol overdose (clove oil), then weighed and measured.Viscera (including the liver and the digestive tract) were removed and also weighed. Complete digestive tracts were then obtained, measured, emptied of intestinal content (IC) by scrapping and divided into the stomach (ST), proximal intestine (PI, including pyloric caeca) and distal intestine (DI) segments. These three segments (ST, PI and DI) and the IC were rapidly frozen $\left(-80^{\circ} \mathrm{C}\right)$ for later enzyme analysis.

Additionally, from S0 to S40, for one fish per tank (three fish per treatment), proximal (placed $2 \mathrm{~cm}$ from the stomach) and distal (placed $2 \mathrm{~cm}$ before the anal orifice) intestinal portions ( $0.5 \mathrm{~cm}$ of length) were stored in $4 \%$ buffered formalin $(\mathrm{pH} 7.2)$ for histological analysis.

\section{Zootechnical indices}

The SGR was calculated as SGR $=[100 \times(\mathrm{ln}$ $\left.\left.W_{\text {fin }}-\ln W_{\text {in }}\right)\right] / t$, where $W_{\text {fin }}$ and $W_{\text {in }}$ stand for the final and the initial weight (tank means), respectively, and $t$ stands for the feeding time (days). The feed conversion rate (FCR) was calculated as FCR = gram feed given per gram live weight gain. The visceral index (VI) was calculated as $\mathrm{VI}=$ (gram visceral weight per gram body weight) $\times 100$ and relative intestinal length (RIL) as RIL = intestinal length $(\mathrm{cm})$ per gram body weight.

\section{Preparation of enzyme extracts}

Enzyme extracts were obtained by manual homogenization of individual samples (S0, S15 and S30) in distilled water $(1: 3 \mathrm{w} / \mathrm{v}$ for the IC and stomach and $1: 2 \mathrm{w} / \mathrm{v}$ for the proximal and distal intestine). The supernatants obtained after centrifugation $\left(16000 \mathrm{~g}, 15 \mathrm{~min}, 4^{\circ} \mathrm{C}\right.$; EBA $12 \mathrm{R}$, Genesys 
Instrumentation S.L., Madrid, Spain) were stored at $-20{ }^{\circ} \mathrm{C}$ for further enzymatic analysis.

\section{Protease activity in digestive extracts}

Acid-protease activity in the stomach and alkalineprotease activity in the proximal and distal intestinal extracts were measured as described by Alarcón, Díaz, Moyano and Abellán (1998). Briefly, acid protease activity was measured by using $5 \mathrm{~g} \mathrm{~L}^{-1}$ haemoglobin in $0.1 \mathrm{M}$ glycine- $\mathrm{HCl}(\mathrm{pH} 2.0)$, while alkaline protease activity was determined by using $5 \mathrm{~g} \mathrm{~L}^{-1}$ casein in $50 \mathrm{mM}$ Tris-HCl (pH 9.0). Samples were incubated for $30 \mathrm{~min}$ at $25^{\circ} \mathrm{C}$ and reactions were stopped by adding $0.5 \mathrm{~mL}$ of TCA $(20 \%)$. The increase in supernatant absorbance was recorded at $280 \mathrm{~nm}$ in a spectrophotometer (Ultrospec 3300 pro; Amersham Pharmacia-Biotech, Cambridge, UK). All measures were performed in triplicate, and the blank for each sample was established by the addition of TCA before enzyme extract. One unit of enzyme activity was defined as $1 \mu \mathrm{g}$ of tyrosine released per minute. Activity was referred to wet sample weight as units per gram of digestive tissue or per gram of the IC respectively.

\section{Effects of diet on protease-active fractions}

Intestinal enzyme extracts were mixed with SDS sample buffer (1:1) and SDS-PAGE were performed according to Laemmli (1970) using $12 \%$ polyacrylamide (100 V per gel, $45 \mathrm{~min}, 4^{\circ} \mathrm{C}$ ). Zymograms revealing protease active bands were carried out according to García-Carreño, Dimes and Haard (1993). Thus, after electrophoresis, gels were washed and incubated in $5 \mathrm{~g} \mathrm{~L}^{-1}$ casein at $4{ }^{\circ} \mathrm{C}$. After $30 \mathrm{~min}$, fresh casein was used and the temperature was increased $(90 \mathrm{~min}$, $37^{\circ} \mathrm{C}$ ). Gels were stained in methanol:acetic-acid: water (40:10:50) containing $1 \mathrm{~g} \mathrm{~L}^{-1}$ Coomassie brilliant blue, and were washed using the same solution without a colorant. Gel images were scanned using Universal Hood II (Bio-Rad, Segarte, Italy).

\section{Intestine histology}

Samples for histological evaluation of the intestinal tract were immersed in phosphate-buffered formalin (4\%, pH 7.2). The samples were subsequently dehydrated and embedded in paraffin according to standard histological techniques. Sections of $5 \mu \mathrm{m}$ were stained with haematoxylin-eosin and examined under light microscopy. A digital camera CC 12 (Soft Imaging System; Muenster, Germany) coupled to an Olympus BX40 light microscope was used to obtain images, and ANALYSIS software (Soft Imaging System) was then used. Intestinal morphology and differences among treatments were evaluated according to the criteria suggested by Krogdahl, Bakke-Mckellep and Baeverfjord (2003): (1) loss of supranuclear vacuolization on enterocytes in the intestinal epithelium, (2) widening of the central lamina propria within intestinal folds and (3) infiltration of leucocytes in lamina propria and submucosa. These alterations are characteristic in salmonids after enteritis induction through the inclusion of soybean meal in aquafeeds (Lilleeng, Froystad, Ostby, Valen \& Krogdahl 2007).

\section{Statistical analysis}

Values are mean \pm SEM (standard error of the mean) of at least three replicate determinations. All data presented a normal distribution $(P>0.05$ in the Kolmogorov-Smirnov test), and were subjected to oneway ANOvA. Differences between means at $P<0.05$ were analysed using the Tukey test. SPSs 12.0 software application (SPSS, IL, USA) was used to perform the analyses.

\section{Chemicals}

All reagents were purchased from Sigma-Aldrich.

\section{Results}

The presence of SBTI in the experimental diets was confirmed by an in vitro inhibition assay. Neither porcine trypsin nor intestinal proteases in sea bream were inhibited by the control diet (Fig. 1). Both SBTI1 and SBTI-2 diets inhibited commercial trypsin and fish intestinal proteases, but no differences were found between both diets. Acid proteases of sea bream were not affected by SBTI at any of the experimental levels tested (Fig. 1b).

No mortality was reported during the trial, and gilthead sea bream consumed all the experimental diets. Fish doubled their initial body weight, showing no significant differences in the final weight and SGR between groups at days 30 and 40 (Table 2). However, fish fed on SBTI-supplemented diets showed lower SGR after 15 days of dietary treatment (S15). No significant differences in FCR, VI or RIL were found for any of the tested diets. 
Aquaculture Research, 2010, 41, e187-e198 Effect of SBTI on growth and digestive proteases of sea bream E Santigosa et al.
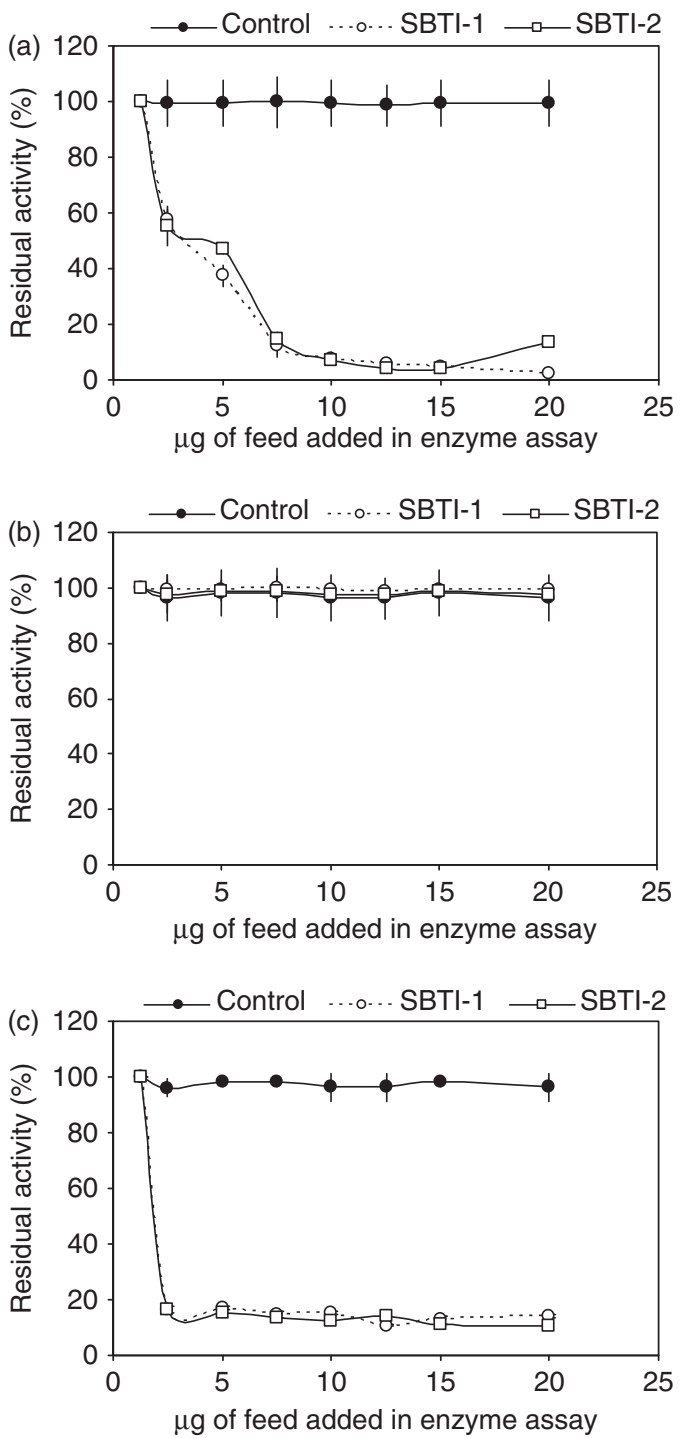

Figure 1 In vitro inhibition test of porcine trypsin (a), sea bream stomach extract (b) and sea bream intestine -extract (c) with experimental diets. The inhibition assays were carried out with $3 \mu \mathrm{g}$ of porcine trypsin (a) or $20 \mu \mathrm{L}$ of sea bream extracts, (b and c) providing equivalent proteolytic activity.

At day 15, acid protease activity in the stomach showed no differences between the control and the SBTI-1 groups (Fig. 2, S15), but fish fed on the SBTI-2 diet presented the highest proteolytic activity in this intestinal segment $(P<0.05)$. On the other hand, acid protease activity at day 30 (S30) revealed maximum activity in the control group, which progressively decreased when the amount of SBTI in the diet increased (up to $-46.6 \%$ in SBTI- 2 fish; $P<0.05)$.
Table 2 Final body weight and zootechnical parameters of the three experimental sea bream groups

\begin{tabular}{|c|c|c|c|}
\hline Parameter & Control & SBTI-1 & SBTI-2 \\
\hline $\begin{array}{l}\text { Initial body } \\
\text { weight (g) }\end{array}$ & $13.58 \pm 0.24$ & $13.50 \pm 0.23$ & $13.57 \pm 0.24$ \\
\hline \multicolumn{4}{|l|}{$\begin{array}{l}\text { Final body } \\
\text { weight }(\mathrm{g})\end{array}$} \\
\hline S15 & $19.41 \pm 0.38$ & $18.65 \pm 0.32$ & $18.97 \pm 0.33$ \\
\hline S30 & $27.08 \pm 0.62$ & $16.19 \pm 0.49$ & $26.78 \pm 0.48$ \\
\hline $\mathrm{S} 40$ & $29.73 \pm 0.62$ & $30.77 \pm 0.63$ & $30.21 \pm 0.90$ \\
\hline \multicolumn{4}{|l|}{ SGR $\left(\% d^{-1}\right)$} \\
\hline S0-S15 & $1.15 \pm 0.05^{\mathrm{a}}$ & $0.94 \pm 0.05^{b}$ & $0.94 \pm 0.04^{b}$ \\
\hline S15-S30 & $0.93 \pm 0.07$ & $0.96 \pm 0.05$ & $0.97 \pm 0.05$ \\
\hline S30-S40 & $0.71 \pm 0.12$ & $0.76 \pm 0.08$ & $0.70 \pm 0.09$ \\
\hline \multicolumn{4}{|l|}{ FCR } \\
\hline S0-S15 & $2.03 \pm 0.13$ & $1.97 \pm 0.07$ & $1.87 \pm 0.06$ \\
\hline S15-S30 & $1.50 \pm 0.14$ & $1.44 \pm 0.13$ & $1.36 \pm 0.10$ \\
\hline S30-S40 & $1.90 \pm 0.05$ & $1.88 \pm 0.10$ & $1.74 \pm 0.06$ \\
\hline \multicolumn{4}{|l|}{ VI } \\
\hline S15 & $11.28 \pm 0.25$ & $10.06 \pm 0.05$ & $10.62 \pm 0.42$ \\
\hline $\mathrm{S} 30$ & $9.80 \pm 0.55$ & $10.91 \pm 0.38$ & $10.50 \pm 0.78$ \\
\hline S40 & $10.67 \pm 0.63$ & $10.98 \pm 0.38$ & $11.32 \pm 0.60$ \\
\hline \multicolumn{4}{|l|}{ RIL $\left(\mathrm{cmg}^{-1}\right)$} \\
\hline S15 & $0.77 \pm 0.05$ & $0.83 \pm 0.03$ & $0.88 \pm 0.05$ \\
\hline S30 & $0.65 \pm 0.03$ & $0.68 \pm 0.40$ & $0.68 \pm 0.04$ \\
\hline S40 & $0.50 \pm 0.03$ & $0.45 \pm 0.02$ & $0.42 \pm 0.02$ \\
\hline Survival (\%) & 100 & 100 & 100 \\
\hline
\end{tabular}

Significant differences $(P<0.05)$ among diets are indicated with lowercase letters. S0, S15, S30 and S40 indicate sampling at 0 , 15,30 and 40 days of trial respectively.

SGR, specific growth rate; FCR, feed conversion rate; VI, viscerosomatic index; RIL, relative intestinal length.

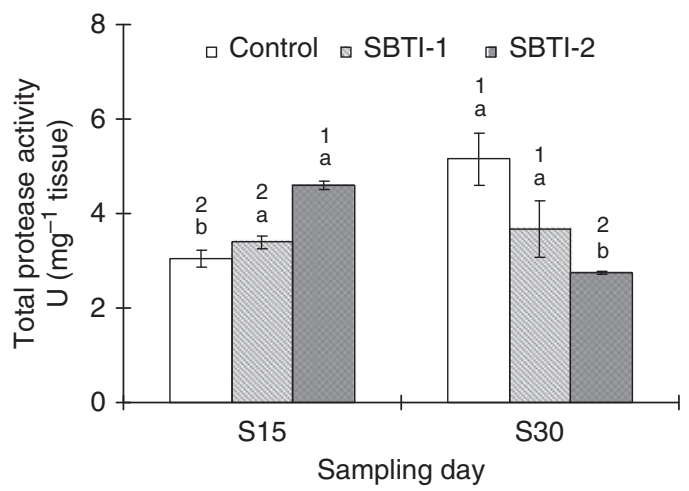

Figure 2 Total acid protease activity in sea bream stomach extracts at $3 \mathrm{~h}$ postfeeding after 15 (S15) or 30 (S30) days of dietary treatment. Values are presented as mean \pm SEM $(n=9) .{ }^{1,2}$ Different numbers denote significant differences between diets of the same sampling day $(P<0.05){ }^{\mathrm{a}, \mathrm{b}}$ Different lowercase letters denote significant differences between sampling days of the same diet $(P<0.05)$. 

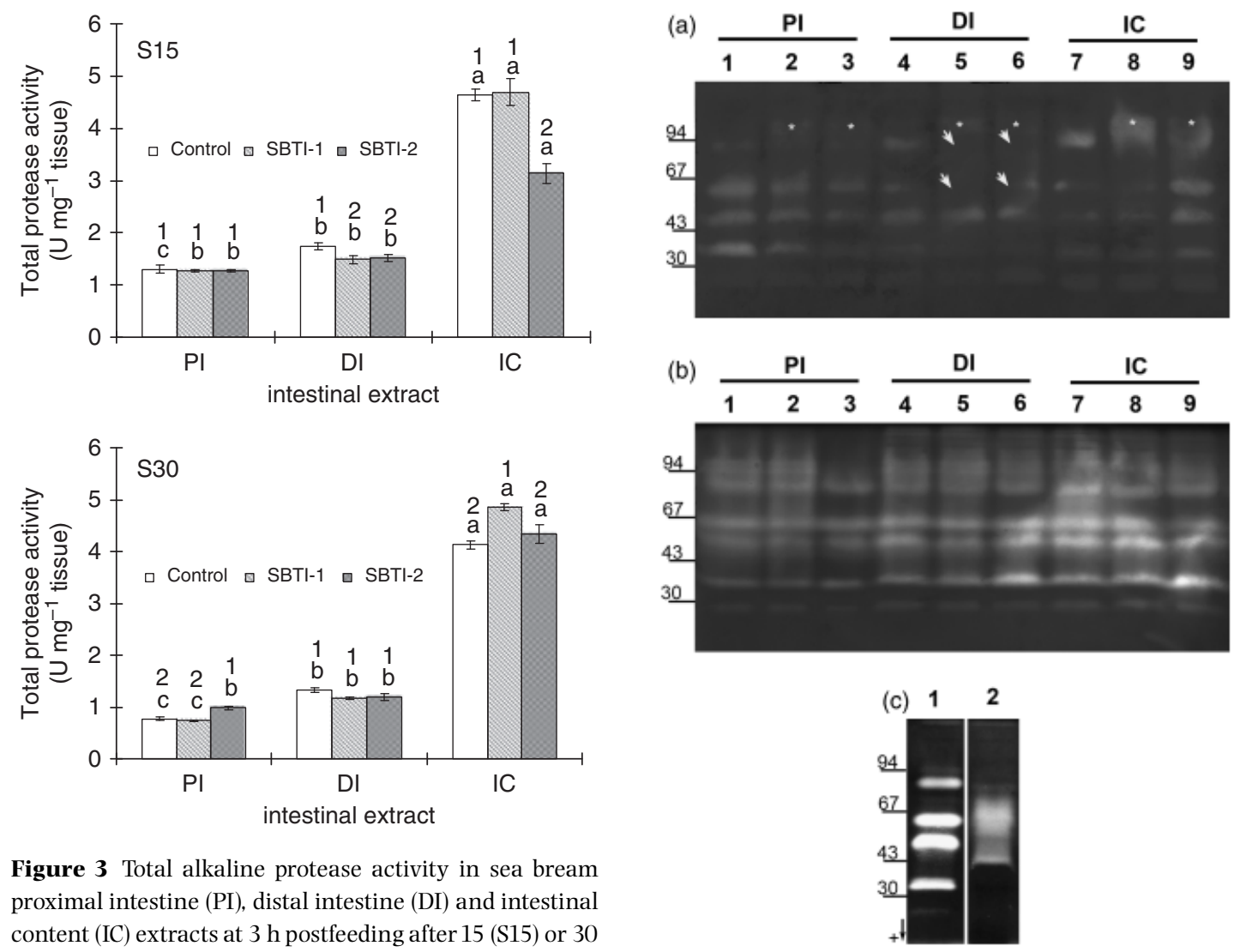

Figure 3 Total alkaline protease activity in sea bream proximal intestine (PI), distal intestine (DI) and intestinal content (IC) extracts at $3 \mathrm{~h}$ postfeeding after 15 (S15) or 30 (S30) days of dietary treatment. Values are presented as mean \pm SEM $(n=9){ }^{1,2}$ Different numbers denote significant differences among diets $(P<0.05)^{\mathrm{a}}{ }^{\mathrm{ab}, \mathrm{c}}$ Different lowercase letters denote significant differences among intestinal extracts in the same diet $(P<0.05)$.

Figure 3 shows the alkaline protease activity measured in the PI, DI and IC at day 15 (S15). This activity was not modified in the proximal intestine when the diet contained SBTI at either of the two tested concentrations, but it was significantly reduced in the distal intestine of fish fed on inhibitor-supplemented diets. Protease activity in the IC decreased significantly only in fish fed on the SBTI-2 diet (Fig. 3, S15). These biochemical findings are supported by the SDS-PAGE results (Fig. 4a). The zymogram shows that SBTI-supplemented diets produced a slight reduction in proteolytic activity in the proximal intestine (Fig. 4a, PI, lanes 2 and 3). This zymogram illustrates that the inhibitor formed high-molecular-weight reversible complexes with intestinal proteases (asterisks show protease-inhibitor complexes over $94 \mathrm{kDa}$ ). However, the inhibition pattern for the distal intestine extracts (Fig. 4a, DI, lanes 5 and 6) was similar to that obtained when sea bream proteases were in-

Figure 4 SDS-PAGE zymograms of sea bream enzyme extracts (PI, proximal intestine; DI, distal intestine; IC, intestinal content) obtained at $3 \mathrm{~h}$ postfeeding after 15 (a) or 30 (b) days of dietary treatment. (a and b) 1, PI control; 2, PI SBTI-1; 3, PI SBTI-2; 4, DI control; 5, DI SBTI-1; 6, DI SBTI-2; 7, IC control; 8, IC-SBTI-1; 9, IC-SBTI-2. Figure 1C shows the zymogram of the proximal intestine extracts of fish feed on the control diet (1, PI control) and the zymogram obtained after a 1-h incubation of these extracts with purified SBTI (2, PI control $+5 \mu \mathrm{g}$ of SBTI). All samples are loaded in equal amounts $(5 \mu \mathrm{L}$ of enzymatic extracts). The apparent molecular size is indicated in kilodalton (kDa). Asterisks $\left(^{*}\right)$ denote reversible proteaseinhibitor complexes of high molecular weight and white arrows denote active fractions inhibited by SBTI.

cubated with purified SBTI (Fig. 4c, lane 2). In those extracts, both the formation of higher-molecularweight complexes (asterisks) and the almost complete inhibition of the two proteolytic fractions over $45 \mathrm{kDa}$ (white arrows) were observed (Fig. 4a, lanes 5 and 6). On the other hand, substrate-SDS-PAGE of the IC of fish fed on SBTI-supplemented diets showed the presence of high-molecular-weight complexes (Fig. 4a; asterisks in lanes 8 and 9). 
At day 30, alkaline protease activity in the PI showed no differences between the control and the SBTI-1 groups, but fish fed on the SBTI-2 diet showed a significant increase in their activity (about $27 \%)(P<0.05)$ (Fig. 3, S30). Protease activity in the DI was similar in the three experimental groups $(P>0.05)$. In the case of the IC, fish fed on the SBTI-1 diet showed the highest proteolytic activity $(P<0.05)$. The zymogram (Fig. $4 b)$ revealed the same qualitative profile for active fractions at day 30.

Figure 3 shows that proteolytic activity presented significant differences between the intestinal segments, with the IC presenting the highest values, followed by those in the DI and, finally, in the PI. Additionally, the intestinal extracts showed differences in their proteolytic activities between the sampling points (SO, S15 and S30). Thus, protease activity in PI reduced significantly in S30 when compared with the S15 and So (1.54 $\pm 0.65 \mathrm{U} \mathrm{mg}^{-1}$ tissue) values. The same pattern was observed for the distal intestine (for SO, DI activity $=2.54 \pm 1.15 \mathrm{U} \mathrm{mg}^{-1}$ tissue). On the other hand, the IC activity decreased significantly only in fish fed on the SBTI-2 diet at the S15 sampling point (for S0, IC activity $=4.93 \pm$ $1.71 \mathrm{U} \mathrm{mg}^{-1}$ tissue).

Histological intestine observation revealed no noticeable differences in the appearance of the proximal or the distal intestine between the three experimental groups at any of the sampling times (Fig. 5), or at the end of the additional 10-day period (S40; data
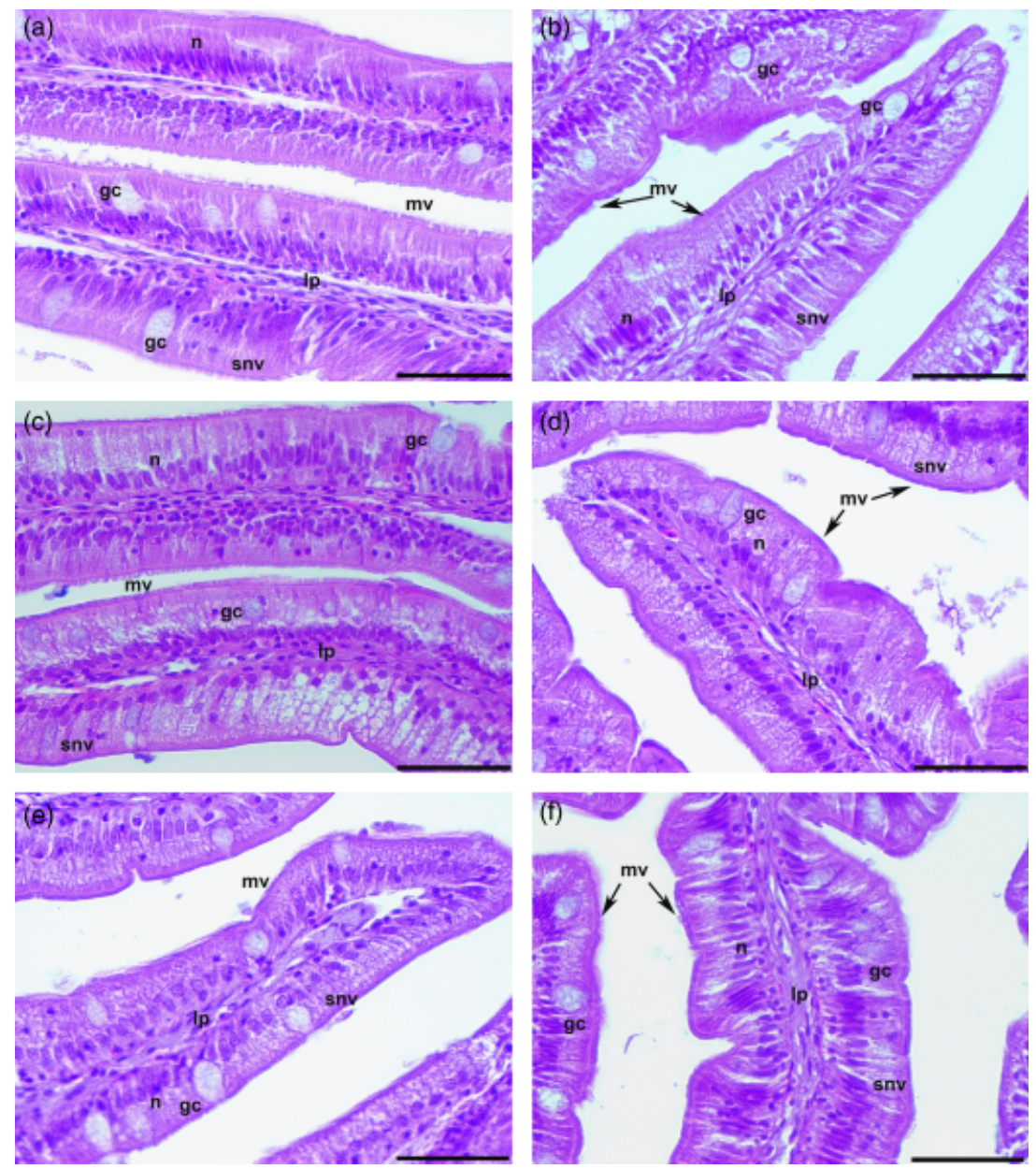

Figure 5 Histological appearance of proximal (left) and distal (right) intestines from sea bream after 30 days of dietary treatment. (a and b) Correspond to samples from fish fed on the control diet; (c and d) correspond to samples from sea bream fed on the SBTI-1 diet; and (e and f) correspond to samples of the SBTI-2 dietary fish group. n, enterocyte nuclei; lp, lamina propria; gc, goblet cells; mv, microvilli and snv, supranuclear vacuoles. (H\&E, objective $\times 40$ ). $20 \mu \mathrm{m}$ scale bar. The same intestinal structure was found in fish at day 0 and after 15 days of dietary treatment (data not shown). 
not shown). Integrity was good in both intestinal segments, and a close approximation of cells with a minimal number of intraepithelial lymphocytes was observed. The lamina propria (lp) appears as a thin layer and cell infiltration was moderate. Differentiated enterocytes, showing a basal nucleus (n), were present along mucosal folds. Intestinal mucosal cells showed a regular shape and well-vacuolated upper (snv), with well-defined microvillar brush borders (mv). Goblet cells (gc) were regularly dispersed throughout the epithelium. Submucosa in SBTI-1 and SBTI-2 groups showed no abnormalities and was identical to that in the control group (data not shown).

\section{Discussion}

Commercial soybean products mainly report trypsin inhibitor activity (TIA) ranging between 2.0 and $6.0 \mathrm{~g} \mathrm{~kg}^{-1}$ (Francis et al. 2001). In the present study, the inclusion of up to $4.0 \mathrm{~g} \mathrm{~kg}^{-1}$ of purified SBTI in diet caused no differences in the final weight or the SGR after 30 days. No decrease in weight gain was likewise observed in other studies in which raw soybean meal (rich in protease inhibitors) was used for sea bream aquafeeds (Robaina et al. 1995; Venou et al. 2006). Moreover, Sveier et al. (2001) demonstrated a positive effect on growth performance when small amounts of protease inhibitor were included in the diet of Atlantic salmon. On the contrary, reduction in the growth performance and nutrient digestibilities had been reported previously in salmonids fed on diets containing purified SBTI at levels below $5 \mathrm{~g} \mathrm{~kg}^{-1}$ in other trials (Krogdahl et al. 1994; Olli et al. 1994). The final FCR, VI and RIL were also unaffected when diets were supplemented with purified SBTI. In a similar way, Sveier et al. (2001) did not find any FCR changes when protease inhibitors were included (up to $5 \mathrm{~g} \mathrm{~kg}^{-1}$ ) in the diet of Atlantic salmon during a 21-day feeding period. By contrast, Peres, Lim and Klesus (2003) reported higher hepatosomatic and viscerosomatic indices in channel catfish when the trypsin inhibitor content in their feed was increased. Santigosa, Sánchez, Médale, Kaushik, Pérez-Sánchez and Gallardo (2008) also reported an increment in the RIL when diet digestibility decreases due to the presence of plant protein sources.

The reduction in protease activity detected in the distal intestine and IC of fish fed on SBTI-supplemented diets at day 15 may be related to the presence of a soybean inhibitor, which inhibits serine proteases through the formation of high-molecular-weight protein complexes (Fig. 4a, lanes 2 and 3). This fact was demonstrated previously by in vitro assays (Alarcón et al. 1999; Moyano et al. 1999) and it could be responsible for the decrease in the intestinal protease activity in sea bream or other fish species when diets contain plant protease inhibitors (Krogdahl et al. 1994; Robaina et al. 1995; Venou, Alexis, Fountoulaki, Nengas, Apostolopoulou \& Castritsi-Cathariou 2003; Lilleeng et al. 2007). The reduction in the protease activity in the IC on increasing the inhibitor in the diet (SBTI-2) agrees with the results obtained by Olli et al. (1994). These authors reported that the reduction observed in the proteolytic activity on increasing dietary SBTI seemed negligible at lower levels $\left(1.05 \mathrm{~g} \mathrm{~kg}^{-1}\right)$ but this inhibitory effect increased considerably at higher levels $\left(4.20 \mathrm{~g} \mathrm{~kg}^{-1}\right)$. However, results at day 30 showed that sea bream juveniles were able to increase protease secretion into the intestinal lumen after a 4-week trial. By contrast, Lilleeng et al. (2007) reported that trypsin activity in the IC of the proximal and mid-intestine of Salmo salar remained significantly lower after 28 days of feeding on a diet with $30 \%$ inclusion of soybean meal (7 $\mathrm{g} \mathrm{TIA} \mathrm{kg}^{-1}$ feed), while Olli et al. (1994) found that the increase in dietary SBTI caused apparent exhaustion of trypsin-synthesizing capacity in this species. In the case of $S$. aurata, the results obtained could be explained by a positive feedback regulation in the mechanism of protease secretion to counteract the reduction in digestion capacity when protease inhibitors are included in the diet (Olli et al. 1994; Haard, Dimes, Arndt \& Dong 1996). In mammals, it was shown that proteolytic activity increased in the gut after SBTI administration (Liddle 1995; Wang, Prpic, Green, Reeve \& Liddle 2002). This fact seems to be mediated by a concurrent cholescystokinin (CCK) secretion stimulated by this protease inhibitor. The release of CCK in the in vivo situation is under negative feedback regulation by proteases present in pancreatic secretion. Active proteases in the intestinal lumen inhibit CCK secretion. The release of CCK is stimulated by a luminal CCK releasing factor (LCRF) that binds to receptors on the secreting cells of the gut. It was shown that under a basal condition, the LCRF is broken down by trypsin and no CCK is secreted. Inhibition of intestinal proteases results in the stimulation of CCK secretion and a subsequent increase in the levels of pancreatic enzymes (Green \& Lyman 1972). Taking this into account, the increase in the intestinal protease activity in sea bream fed on SBTI-supplemented diets at day 30 could thus be 
explained, but to date, it remains unclear in this species and requires further research.

No explanation has been found for changes in acid protease activity between the two sampling points in the present study. Sveier et al. (2001) reported that proteolytic activity in the stomach of $S$. salar fed on high levels of potato protease inhibitor decreased after a 21-day period. However, these authors did not provide any explanation for this fact. Undoubtedly, inhibition of stomach proteases by soybean inhibitor must be discarded, because SBTI-supplemented diets did not affect fish acid proteases (Fig. 1). In rats, it has been reported that SBTI stimulates the secretion of gastrin (Temler, Dormond, Simon \& Morel 1985). Johnson (2001) indicates that gastrin could influence the secretion of pepsinogen. In the case of sea bream, it can be hypothesized that these variations could be caused by negative feedback due to the presence of an inhibitor at the intestinal level, but further research is needed to clarify this point.

A progressive reduction in the alkaline proteolytic activity was found in the trial, with S15 extracts showing a higher proteolytic activity than those for S30 ones. Olli et al. (1994) described the same findings for $S$. salar fed on SBTI-supplemented diets. In their study, trypsin activity in the same intestinal segment increased along the sampling time (12 and 31 days), independent of the presence or absence of a protease inhibitor. Obviously, these variations are influenced by the continuous growth of digestive organs in juvenile fish, which influence protease activity depending on the sampling time point. Keeping this in mind, differences in protease activity among sampling times could be due to both digestive growth and/or the presence of protease inhibitor in the diet, thus not allowing clear conclusions when comparing activities from different sampling days.

Alkaline protease activity was different between intestinal segments and, in general, higher values were reported in the DI. The distribution of digestive enzymes along the intestine of sea bream does not seem to be specific for any part of the gut, the distal intestine being characterized by a higher proteolytic activity. This pattern of distribution of digestive proteases seems to be specific for S. aurata as Psochiou, Mamuris, Panagioataki, Kounetas and Moutou (2007) described.

The present study shows that the administration of SBTI-supplemented diets caused no histopathologic alterations during a 30-day period. This agrees with many trials where no differences in gut appearance were reported. For instance, the intestinal histology of Egyptian sole revealed no significant differences between fish fed on a fish-meal-based diet and a diet containing $300 \mathrm{~g} \mathrm{~kg}^{-1}$ soybean meal during an 87-day feeding trial (Bonaldo, Roem, Pecchini, Grilli \& Gatta 2006). Neither Atlantic halibut fed on $360 \mathrm{~g} \mathrm{~kg}^{-1}$ soybean-meal diets nor channel catfish fed on a diet with $450 \mathrm{~g} \mathrm{~kg}^{-1}$ soybean meal showed intestinal changes after a 60-day trial (GrisdaleHelland, Helland, Baeverfjord \& Berge 2002). On the contrary, our results contrast with many other reports where severe histological alterations are related to the presence of soybean antinutritional factors. Thus, Krogdahl et al. (2003) found histopathologic changes in salmon intestine due to the inclusion of $100 \mathrm{~g} \mathrm{~kg}^{-1}$ of soybean meal in a 60-day feeding experiment. Bonaldo et al. (2008) reported morphological alterations in the distal intestine of sea bream fed on a diet with $300 \mathrm{~g} \mathrm{~kg}^{-1}$ of soybean meal for 80 days. Furthermore, Lilleeng et al. (2007) described enteritis in the distal intestine of salmon fed on a soybean diet for 28 days. Boonyaratpalin, Suraneiranat and Tunpinabal (1998) described highly vacuolated enterocytes with eosinophilic inclusion in Asian sea bass fed on an extruded soybean-meal diet for 10 weeks. The present results, showing no intestinal histological modifications, can therefore be attributed to the specific sensitivity of certain fish species. Another possible explanation is that gut morphological changes described by other authors may have been caused by the presence of lectins, allergenic proteins or alcohol soluble components present in soybean instead of the protease inhibitor tested in this work (Van Den Ingh, Olli \& Krogdahl 1996; Francis et al. 2001). The results obtained in this study show that SBTI do not produce enterocyte and gut morphological alterations during mid-term feeding periods.

\section{Conclusion}

The inclusion of up to $4.0 \mathrm{~g} \mathrm{~kg}^{-1}$ SBTI (i) reduces sea bream intestinal proteolytic activity at the beginning of its administration through the formation of highmolecular-weight complexes with serine proteases (although sea bream juveniles are able to overcome protease inhibitor effects within a 30-day feeding trial) and (ii) does not affect intestinal histology. At the end of the trial, fish fed on SBTI-supplemented diets showed final weights, proteolytic activities and intestinal histological appearance similar to those found in fish fed on the inhibitor-free diet. 


\section{Acknowledgments}

The authors thank PREDOMAR fishery (Carboneras, Almería, Spain) for fish supply, and the Instituto Nacional de Investigación y Tecnología Agraria y Alimentaria (RTA2007-00026-C02-02), Junta de Andalucía (project AGR-1842) and the European Regional Development Fund for financial support. Ester Santigosa was supported by a grant provided by the Agència de Gestió d'Ajuts Universitaris i Recerca of the Catalonian Regional Government (Generalitat de Catalunya). The authors are grateful to Dr Alicia Moguilevsky and Francisco Trujillo for the revision of the English language text.

\section{References}

Alarcón F.J., Díaz M., Moyano F.J. \& Abellán E. (1998) Characterization and functional properties of digestive proteases in two sparids; gilthead seabream (Sparus aurata) and common dentex (Dentex dentex). Fish Physiology and Biochemistry 19, 257-267.

Alarcón F.J., Moyano F.J. \& Díaz M. (1999) Effect of inhibitors present in protein sources on digestive proteases of juvenile seabream (Sparus aurata). Aquatic Living Resources 12, 233-238.

Alarcón F.J., García-Carreño F.L. \& Navarrete del Toro M.A. (2001) Effect of plant protease inhibitors on digestive proteases in two fish species, Lutjanus argentiventris and L. novemfasciatus. Fish Physiology and Biochemistry 24, 179-181.

Anderson R.L. \& Wolf W.J. (1995) Compositional changes in trypsin inhibitors, phytic acid, saponins and isoflavones related to soybean processing. Journal of Nutrition $\mathbf{1 2 5}$, 585S-588S.

Bonaldo A., Roem A.J., Pecchini A., Grilli E. \& Gatta P.P. (2006) Influence of dietary soybean meal levels on growth, feed utilization and gut histology of Egyptian sole (Solea aegyptiaca) juveniles. Aquaculture 261, 580-586.

Bonaldo A., Roem A.J., Fagioli P., Pecchini A., Cipollini I. \& Gatta P.P. (2008) Influence of dietary levels of soybean meal on the performance and gut histology of gilthead sea bream (Sparus aurata L.) and European sea bass (Dicentrarchus labrax L.). Aquaculture Research 39, 979-978.

Boonyaratpalin M., Suraneiranat P. \& Tunpinabal T. (1998) Replacement of fish meal with various types of soybean products in diet for the Asian seabass, Lates calcarifer. Aquaculture 161, 67-78.

Choi S.M., Wang X., Park G.J., Lim S.R., Kim K.W., Bai S.C. \& Shin I.S. (2004) Dietary dehulled soybean meal as a replacement for fish meal in fingerling and growing dine flounder Paralichthys olivaceus. Aquaculture Research 35 , 410-418.

Dabrowski K., Poczyczynski P., Kock G. \& Berger B. (1989) Effect of partially or totally replacing fish meal protein by soybean-meal protein on growth, food utilization and proteolytic enzyme activities in rainbowtrout (Salmo gairdneri) - new in vivo test for exocrine pancreatic-secretion. Aquaculture 77, 29-49.

El-Sayed A.F.M., Martínez I. \& Moyano F.J. (2000) Assessment of the effect of plant inhibitors on digestive proteases of Nile tilapia using in vitro assays. Aquaculture International 8, 403-415.

Francis G., Makkar H.P.S. \& Becker K. (2001) Antinutritional factors present in plant-derived alternate fish feed ingredients and their effects in fish. Aquaculture 199, 197-227.

Gallagher M.L. (1994) The use of soybean meal as a replacement for fish-meal in diets for hybrid striped bass (Morone saxatilis X Morone chrysops). Aquaculture 126, 119-127.

García-Carreño F.L., Dimes L.E. \& Haard N.F. (1993) Substrate gel-electrophoresis for composition and molecular-weight of proteinases of proteinaceous proteinaseinhibitors. Analytical Biochemistry 214, 65-69.

Gomes E.F., Rema P. \& Kaushik S.J. (1995) Replacement of fish-meal by plant-proteins in the diet of rainbow trout (Oncorhynchus-mykiss) - digestibility and growth-performance. Aquaculture 130, 177-186.

Grant G. (1991) Lectins. In: Toxic Substances in Crop Plants (ed. by F.J.P. D’Mello, C.M. Duffus \& J.P. Duffus), pp. 49-67. Royal Society of Chemistry, Cambridge, UK.

Green G.M. \& Lyman R.L. (1972) Feedback regulation of pancreatic enzyme secretion as a mechanism for trypsin inhibitor-induced hypersecretion in rats. Proceding of the Society for Experimental Biology and Medicine 140, 6-12.

Grisdale-Helland B., Helland S.J., Baeverfjord G. \& Berge G.M. (2002) Full-fat soybean meal in diets for Atlantic halibut. Growth, metabolism and intestinal histology. Aquaculture Nutrition 8, 265-270.

Haard N.F., Dimes L.E., Arndt R.E. \& Dong F.M. (1996) Estimation of protein digestibility. IV. Digestive proteinases from pyloric caeca of Coho salmon (Oncorhynchus kisutch) fed diets containing soybean meal. Comparative Biochemistry and Physiology Part B 115, 533-540.

Johnson L.R. (2001) Gastric secretion. In: Gastrointestinal Physiology (ed. by L.R. Johnson \& T.A. Gerwin), 6th edn. (pp. 75-94. Mosby, St Louis, MI, USA.

Kaushik S.J., Cravedi J.P., Lalles J.P., Sumpter J., Fauconneau B. \& Laroche M. (1995) Partial or total replacement of fishmeal by soybean protein on growth, protein-utilization, potential estrogenic or antigenic effects, cholesterolemia and flesh quality in rainbow-trout, Oncorhynchus mykiss. Aquaculture 133, 257-274.

Kissil G.W., Lupatsch I., Higgs D.A. \& Hardy R.W. (2000) Dietary substitution of soy and rapeseed protein concentrates for fish meal, and their effects on growth and nutrient utilization in gilthead seabream Sparus aurata. Aquaculture Research 31, 595-601.

Knudsen D., Ron O., Baardsen G., Smedsyaard J., Koppe W. \& Frokiaer H. (2006) Soyasaponins resist extrusion cooking and are not degraded during gut passage in Atlantic 
salmon (Salmo salar L.). Journal of Agricultural and Food Chemistry 55, 2261-2267.

Krogdahl A. \& Holm H. (1983) Pancreatic proteinases from man, trout, rat, pig, cow, chicken, mink and fox. Enzyme activities and inhibition by soybean and limabean proteinase inhibitors. Comparative Biochemistry and Physiology Part B 74, 403-409.

Krogdahl A., Lea T.B. \& Olli J.L. (1994) Soybean proteinase inhibitors affect intestinal trypsin activities and amino acid digestibilities in rainbow trout (Oncorhynchus mykiss). Comparative Biochemistry and Physiology Part A 107, 215-219.

Krogdahl A., Bakke-Mckellep A.M. \& Baeverfjord G. (2003) Effects of graded levels of standard soybean meal on intestinal structure, mucosal enzyme activities, and pancreatic response in Atlantic salmon (Salmo salar L.). Aquaculture Nutrition 9, 361-371.

Laemmli U.K. (1970) Cleavage of structural proteins during assembly of head of bacteriophage-T4. Nature 227, 680-688.

Liddle R.A. (1995) Regulation of cholecystokinin secretion by intraluminal releasing factors. American Journal of Physiology 269, G319-G327.

Lilleeng E., Froystad M.K., Ostby G.C., Valen E.C. \& Krogdahl A. (2007) Effect of diets containing soybean meal on trypsin mRNA expression and activity in Atlantic salmon (Salmo salar L). Comparative Biochemistry and Physiology Part A 147, 25-36.

Lim C. \& Akiyama D.M. (1992) Full-fat soybean utilization by fish. Asian Fisheries Science 5, 181-197.

Makkar H.P.S. (1993) Antinutritional factors in foods for livestock. In: Animal Productions in Developing Countries, Vol.16 (ed. by Gill M.Owen E., Pollot G.E. \& Lawrence T.L.J.), pp. 69-85. British Society of Animal Production, Edinburgh, UK.

Moyano F.J., Martínez I., Díaz M. \& Alarcón F.J. (1999) Inhibition of digestive proteases by vegetable meals in three fish species; seabream (Sparus aurata), tilapia (Oreochromis niloticus) and African sole (Solea senegalensis). Comparative Biochemistry and Physiology Part B 122, 327-332.

NRC, National Research Council. (1993) Nutritional Requirements of Fish, 114. National Academic Press, Washington, DC, USA.

Oliva-Teles A., Gouveia A.J., Gomes E. \& Rema P. (1994) The effect of different processing treatments on soybean meal utilization by rainbow trout, Oncorhynchus mykiss. Aquaculture 124, 343-349.

Olli J.J., Hjelmeland K. \& Krogdal A. (1994) Soybean trypsin inhibitors in diets for Atlantic salmon (Salmo salar L.): effects on nutrient digestibilities and trypsin in pyloric caeca homogenate and intestinal content. Comparative Biochemistry and Physiology Part A 109, 923-928.

Olsen R.E., Hansen A.C., Roselund G., Hemre G.I., Mayhew T.M., Knudsen D.L., Eroldogan O.T., Myklebust R. \& Karlsen O. (2007) Total replacement of fish meal with plant proteins in diets for Atlantic cod (Gadus morhua L.) II- Health aspects. Aquaculture 272, 612-624.
Ostaszewska T., Dabrowski K., Palacios M.E., Olejniczak M. \& Wieczorek M. (2005) Growth and morphological changes in the digestive tract of rainbow trout (Oncorhynchus mykiss) and pacu (Piaractus mesopotamicus) due to casein replacement with soybean proteins. Aquaculture 245, 273-286.

Pelissero C., Bennetau B., Babin P., Lemenn F. \& Dunogues J. (1991) The estrogenic activity of certain phytoestrogens in the Siberian sturgeon Acipenser baeri. Journal of Steroid Biochemistry and Molecular Biology 38, 293-299.

Peres H., Lim C. \& Klesus P.H. (2003) Nutritional value of heat-treated soybean meal for channel catfish (Ictalurus punctatus). Aquaculture 225, 67-82.

Psochiou E., Mamuris Z., Panagioataki P., Kounetas D. \& Moutou K.A. (2007) The response of digestive proteases to abrupt salinity decrease in the euryhaline sparid Sparus aurata L. Comparative Biochemistry and Physiology Part B 147, 156-163.

Refstie S., Storebakken T. \& Roem A. (1998) Feed consumption and conversion in Atlantic salmon (Salmo salar) fed diets with fish meal, extracted soybean meal or soybean meal with reduced content of oligosaccharides, trypsin inhibitors, lectins and soya antigens. Aquaculture $\mathbf{1 6 2}$, 301-312.

Refstie S., Korson O.J., Storebakken T., Baeverfjord G., Lein I. \& Roem A.J. (2000) Differing nutritional responses to dietary soybean meal in rainbow trout (Oncorhynchus mykiss) and Atlantic salmon (Salmo salar). Aquaculture 209, 49-63.

Richardson N.L., Higgs D.A., Beames R.M. \& McBride J.R. (1985) Influence of dietary calcium, phosphorus, zinc and sodium phytate level on cataract incidence, growth and histopathology in juvenile Chinook salmon (Oncorhynchus tshawytscha). Journal of Nutrition 115, 553-567.

Robaina L., Izquierdo M.S., Moyano F.J., Socorro J., Vergara J.M., Montero D. \& Fernández-Palacios H. (1995) Soybean and lupin seed meals as protein-sources in diets for gilthead seabream (Sparus aurata) - Nutritional and histological implications. Aquaculture 130, 219-233.

Santigosa E., Sánchez J., Médale F., Kaushik S., PérezSánchez J. \& Gallardo M.A. (2008) Modifications of digestive enzymes in trout (Oncorhynchus mykiss) and sea bream (Sparus aurata) in response to dietary fish meal replacement by plant protein sources. Aquaculture 282, 68-74.

Sanz A., Morales A.E., de la Higuera M. \& Cardenete G. (1994) Sunflower meal compared with soybean meal as partial substitutes for fish meal in rainbow trout (Oncorhynchus mykiss) diets - protein and energy-utilization. Aquaculture 128, 287-300.

Sveier H., Kuamme B.O. \& Raae A.J. (2001) Growth and protein utilization in Atlantic salmon (Salmo salar L.) given a protease inhibitor in diet. Aquaculture 7, 255-264.

Temler R.S., Dormond C.A., Simon E. \& Morel B. (1985) The effect of feeding soya bean trypsin inhibitor and repeated injections of cholecystokinin on rat pancreas. Quality of Plant Foods for Human Nutrition 35, 315-321. 
Van Den Ingh T.S.G.A., Olli J.J. \& Krogdahl A. (1996) Alcohol soluble components in soybeans cause morphological changes in the distal intestine of Atlantic salmon, Salmo salar L. Journal of Fish Disease 19, 47-53.

Venou B., Alexis M.N., Fountoulaki E., Nengas I., Apostolopoulou M. \& Castritsi-Cathariou I. (2003) Effect of extrusion of wheat and corn on gilthead seabream (Sparus aurata) growth, nutrient utilization efficiency, rates of gastric evacuation and digestive enzyme activities. Aquaculture 225, 207-223.
Venou B., Alexis M.N., Fountoulaki E. \& Haralabous J. (2006) Effects of extrusion and inclusion level of soybean meal on diet digestibility, performance and nutrient utilization on gilthead seabream (Sparus aurata). Aquaculture 261, 343-356.

Wang Y., Prpic V., Green D.M., Reeve J.R. \& Liddle R.A. (2002) Luminal CCK-releasing factor stimulates CCK release from human intestinal endocrine and STC-1 cells. American Journal of Physiology - Gastrointestinal and Liver Physiology 282, 16-22. 